\title{
Pulmonary sarcoidosis with a diffuse ground glass pattern on the chest radiograph
}

\author{
Abdellatif Tazi, Tsellina Desfemmes-Baleyte, Paul Soler, Dominique Valeyre, \\ Allan J Hance, Jean-Paul Battesti
}

\begin{abstract}
Background-Several chest radiographic abnormalities have been described in pulmonary sarcoidosis, but a diffuse ground glass pattern is extremely rare.

Methods-The chest radiographs of more than 1600 patients with sarcoidosis evaluated in our service between 1976 and 1991 were reviewed to determine the prevalence of this pattern on chest radiography at presentation, and to assess the clinical characteristics of these patients. Results-Ten patients $(0.6 \%)$ were identified with diffuse ground glass abnormalities on the chest radiograph (eight men); all had associated hilar or mediastinal adenopathy. All patients were white and nine were smokers or former smokers. Nine patients were symptomatic and six had inspiratory crackles on physical examination. As a group these patients were remarkable for the frequency and severity of physiological abnormalities and the presence of various findings typically associated with "active" disease. Nine patients were followed for more than three years. All were treated with oral corticosteroids because of significant symptoms or physiological abnormalities, or both. Symptoms and radiological abnormalities disappeared or improved in all patients, but recurred in a high proportion when steroids were tapered or discontinued. By December 1992 only three patients had been withdrawn from treatment.
\end{abstract}

Conclusions-A diffuse ground glass pattern on the chest radiograph is unusual in patients with sarcoidosis and may occur more commonly in white subjects and cigarette smokers. Its presence suggests the existence of active disease of recent onset likely to require long term treatment with corticosteroids.

(Thorax 1994;49:793-797)

Sarcoidosis is a multisystem disorder of unknown aetiology characterised by the presence of non-caseating granulomas at sites of involvement. ${ }^{1-4}$ Although most organs can be affected by the disease, the lung and thoracic lymph nodes are the most common sites and approximately $90 \%$ of patients with sarcoidosis have an abnormal chest radiograph. ${ }^{1-4}$

Various radiographic patterns have been described in patients with pulmonary parenchymal involvement. In patients with parenchymal abnormalities a reticulonodular pattern is most commonly observed, ${ }^{5}$ but other less common patterns have been reported. ${ }^{5-7}$ A diffuse ground glass pattern - defined as a homogeneous opacification in which normal anatomical details of the lung are still visible but giving a hazy appearance to the lung fields ${ }^{8}$ - is mainly observed in hypersensitivity pneumonitis, particularly in the acute form of farmer's lung, ${ }^{9}$ and has also been described in some patients with early stages of asbestosis and berylliosis. ${ }^{8} \mathrm{~A}$ diffuse ground glass pattern on the standard chest radiograph is extremely rare in sarcoidosis, although ground glass opacities (usually localised) have been observed with high resolution computed tomographic scanning of the lung. ${ }^{1011}$

We have recently encountered a patient with sarcoidosis who presented with a ground glass pattern on chest radiography. To further investigate this association we have reviewed radiographs of more than 1600 patients with sarcoidosis evaluated at our unit to determine the prevalence of a diffuse ground glass pattern at the time of diagnosis and to better define the clinical characteristics and prognosis of these patients.

\section{Methods}

STUDY POPULATIONS

All patients with pulmonary sarcoidosis evaluated at Hôpital Avicenne between January 1976 and December 1991 were included. The diagnosis of sarcoidosis was based on previously described criteria, including the presence of non-caseating granulomas in a biopsy specimen of involved tissue or the site of a KveimSiltzbach reaction. ${ }^{12}$ Patients whose chest radiograph taken at diagnosis demonstrated a diffuse ground glass pattern - defined as a homogeneous opacity affecting both lungs and in which normal anatomical details are still visible - were identified and their medical records reviewed. Epidemiological data (including age, sex, ethnic group, current and past smoking habits) and clinical history were available for all patients. Apart from routine biological tests, blood and urine calcium concentrations were also noted. Serum angiotensin converting enzyme activity was assayed with hippuryl histidine leucine as a substrate. ${ }^{13}$

\section{PULMONARY FUNCTION TESTS}

The forced expiratory volume in one second $\left(\mathrm{FEV}_{1}\right)$ and vital capacity (VC) were measured with a spirometer (Godart water sealed spirometer) and residual volume (RV) by multiple breath helium dilution. Carbon monoxide transfer factor ( $\mathrm{T}_{L C O}$ ) was measured by the 
single breath method and scaled for age and height or alveolar volume (VA) as specified. The results were compared with previously published standards. ${ }^{13}$

\section{BRONCHOALVEOLAR LAVAGE}

All patients who underwent bronchoalveolar lavage as part of the diagnostic evaluation gave informed consent before the procedure. Lavage was performed as previously described using five aliquots $\left(50 \mathrm{ml}\right.$ each) of sterile saline. ${ }^{12}$ The total number of cells recovered $/ \mathrm{ml}$ lavage fluid was determined by counting cells present in an aliquot of the resuspended original fluid. Differential cell count was obtained on May-Grünwald-Giemsa stained cytocentrifuged preparations of the lavage fluid by counting at least 500 cells.

\section{STATISTICAL METHODS}

Results are expressed as mean (SD). Comparisons of sequential data were made using a paired $t$ test, a probability of $<0.05$ being considered significant.

\section{Results}

CHARACTERISTICS OF PATIENTS WITH PULMONARY SARCOIDOSIS AND A DIFFUSE GROUND GLASS RADIOGRAPHIC PATTERN AT THE TIME OF DIAGNOSIS

Clinical, biological and radiological findings

Between January 1976 and December 1991 1652 patients with sarcoidosis were evaluated at our unit. Ten patients $(0.6 \%)$ had a diffuse ground glass pattern in the lung fields on a chest radiograph performed at the time of diagnosis. In these individuals the diagnosis of sarcoidosis was based on the presence of a compatible clinical picture, no evidence of disease due to other agents known to produce granulomatous lung diseases, and the presence of typical noncaseating granulomas on tissue biopsy samples (skin $(n=1)$, bronchial mucosa $(n=4)$, lymph

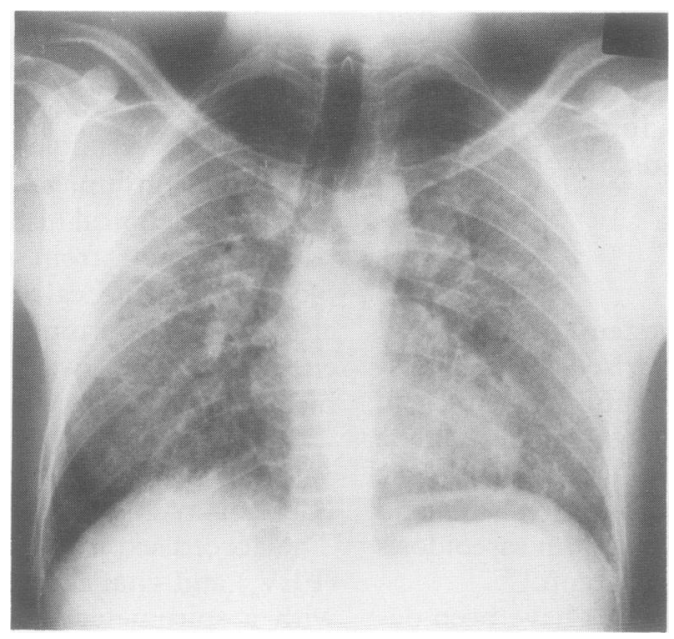

Typical chest radiograph from a patient with sarcoidosis with a diffuse ground glass pattern. Note the existence of bilateral hilar and mediastinal adenopathy. nodes $(\mathbf{n}=3)$ ), or at the site of a KveimSiltzbach reaction $(n=2)$. All patients had coexistent bilateral hilar or mediastinal adenopathy, or both. A typical chest radiograph of one of these patients is shown in the figure. Previous chest radiographs were available for four patients and all were normal two, six, nine, and twelve months respectively before presentation. Two patients underwent thoracic high resolution computed tomographic scanning as part of the diagnostic evaluation and the presence of ground glass abnormalities was confirmed in both cases.

The epidemiological and clinical findings of the 10 patients are summarised in table 1 . Nine of the patients were symptomatic at the time of diagnosis. Nine had smoked cigarettes; the six who were current smokers smoked more than 20 cigarettes/day (mean (SD) 25 (8)). Six patients had bilateral inspiratory crackles predominantly at the lung bases. Seven patients had extrathoracic lesions at one or more sites (peripheral lymph nodes $(n=4)$, ocular $(\mathrm{n}=2)$, skin $(\mathrm{n}=1)$, liver and spleen $(\mathrm{n}=1)$, parotids $(n=1)$, peripheral nerves $(n=1)$, and bone $(n=1)$ ). Although no patient had hypercalcaemia, an increase in the daily urinary calcium excretion $(>0.1 \mathrm{mmol} / \mathrm{kg} /$ day $)$ was noted in five of eight cases studied at the time of initial evaluation. Serum levels of angiotensin converting enzyme were elevated for all patients, ranging from two to five times the maximal normal value.

\section{Pulmonary function}

Results of pulmonary function tests were available for eight patients at the time of diagnosis. Seven patients had a restrictive defect, defined by a TLC of $<80 \%$ predicted $(67 \cdot 8(12 \cdot 5) \%)$. The TLco adjusted for age and height was considerably impaired in all cases (48.4 (13)\% of predicted) and five of eight patients had a TLCO/VA of $<80 \%$ predicted $(71(17 \cdot 7) \%)$. Arterial hypoxaemia $\left(\mathrm{PaO}_{2}<10.6 \mathrm{kPa}\right)$ was present at rest in five of eight patients.

\section{Bronchoalveolar lavage}

Since patients evaluated as early as 1976 were included in this study, lavage results were avail-

Table 1 Epidemiological and clinical features of patients with sarcoidosis who presented with diffuse ground glass abnormalities on the chest radiograph

\begin{tabular}{ll}
\hline Clinical characteristics & $\begin{array}{l}\text { No. of patients } \\
(n=10)\end{array}$ \\
\hline Epidemiological features & \\
Mean (SD) age (years) & $38 \cdot 5(11 \cdot 5)$ \\
M:F & $8: 2$ \\
Smoking history & 6 \\
$\quad$ Current & 3 \\
$\quad$ Former & 1 \\
None & 10 \\
Race & \\
White & \\
Clinical signs and symptoms & 7 \\
Cough & 8 \\
Exertional dyspnoea & 5 \\
Weight loss & 6 \\
Inspiratory rales & 7 \\
Extrathoracic localisation & \\
\hline
\end{tabular}


Table 2 Results of bronchoalveolar lavage in six patients with sarcoidosis who presented with a diffuse ground glass pattern on the chest radiograph

\begin{tabular}{|c|c|c|c|c|c|c|}
\hline \multirow{2}{*}{$\begin{array}{l}\text { Smoking } \\
\text { history }\end{array}$} & \multirow{2}{*}{$\begin{array}{l}\text { Total cells/ml } \\
\left(\times 10^{-3}\right)\end{array}$} & \multicolumn{5}{|c|}{ Percentage of cells } \\
\hline & & Macrophages & Lymphocytes & Neutrophils & Eosinophils & Mast cells \\
\hline $\begin{array}{l}\text { NS } \\
\text { FS } \\
\text { S } \\
\text { S } \\
\text { S } \\
\text { FS }\end{array}$ & $\begin{array}{l}145 \\
115 \\
395 \\
791 \\
645 \\
150\end{array}$ & $\begin{array}{l}48 \\
24 \\
45 \cdot 5 \\
43 \\
78 \cdot 5 \\
52\end{array}$ & $\begin{array}{l}51 \\
76 \\
53 \\
50 \\
18 \\
48\end{array}$ & $\begin{array}{l}1 \\
0 \\
0 \\
6 \\
2 \\
0\end{array}$ & $\begin{array}{l}0 \\
0 \\
0 \\
0 \\
1 \\
0\end{array}$ & $\begin{array}{l}0 \\
0 \\
1 \cdot 5 \\
1 \\
0.5 \\
0\end{array}$ \\
\hline
\end{tabular}

NS = non-smoker; $F S=$ former smoker; $S=$ current smoker.

able for only six patients. The number of lymphocytes/ml lavage fluid was increased in all patients (table 2). The CD4/CD8 lymphocyte ratio was evaluated in two smokers and was $4 \cdot 2$ and 2.6 respectively. Increased numbers of inflammatory cells were generally not present although one patient, a current smoker, had a moderate increase in neutrophils in the lavage fluid. Three of the six patients evaluated had an increased percentage of mast cells in the lavage fluid $(\geqslant 0.5 \%) .{ }^{14}$

\section{OUTCOME}

Nine patients were followed for more than three years (mean (SD) 99 (38) months, range 36-146 months). Because all these patients initially had significant respiratory symptoms (dyspnoea and/or cough) or severely impaired lung function, or both, all received treatment with oral corticosteroids $(0.5 \mathrm{mg} / \mathrm{kg} /$ day prednisone $)$. They all improved with treatment and inspiratory crackles disappeared in all cases within three months. Similarly, parenchymal abnormalities on the chest radiographs disappeared within three months of the institution of corticosteroids in seven of the nine patients and were considerably improved in the remaining two. Lung function tests also improved with treatment (table 3). For all patients studied $(\mathrm{n}=7)$ TLC returned to within the predicted range during treatment. In parallel, TLCO adjusted for age and height increased by $>10 \%$ in five of seven cases, although TLCO/VA was not significantly modified (table 3 ). $\mathrm{PaO}_{2}$ at rest reached normal values $(>10.6 \mathrm{kPa})$ in three of the five patients who were initially hypoxaemic and improved in two other cases.

Although all patients showed initial improvement six of the nine patients experienced recur-

Table 3 Sequential evaluation of mean (SD) results of respiratory function testing for seven patients with sarcoidosis who presented with a diffuse ground glass pattern at the time of diagnosis and after treatment with corticosteroids

\begin{tabular}{lll}
\hline Physiological test & Before treatment & After treatment \\
\hline TLC (\% predicted) & $66 \cdot 8(13 \cdot 2)$ & $89(7 \cdot 2)^{*}$ \\
FEV $_{1} / \mathrm{VC}$ & $78 \cdot 0(12 \cdot 3)$ & $77 \cdot 4(9 \cdot 3)$ \\
TLCO $_{\text {T } \% \text { predicted) }}$ & $49 \cdot 1(13 \cdot 8)$ & $66 \cdot 8(13 \cdot 6)^{*}$ \\
TLCO $/ \mathrm{VA}^{\mathrm{PaO}}$ (kPa) & $72 \cdot 5(19 \cdot 0)$ & $73 \cdot 5(9 \cdot 7)$ \\
\hline
\end{tabular}

${ }^{*} p<0.05$ comparing results before and after treatment using a paired $t$ test. The best lung function while the patient was
receiving corticosteroids was chosen. rent signs and symptoms of active sarcoidosis while their doses of prednisone were being tapered or after interruption of treatment. Strikingly, during these recurrent episodes of sarcoidosis the chest radiographs always showed a diffuse ground glass pattern. Four patients had multiple episodes of recu: rent sarcoidosis. Overall the duration of treatment was 96 (41) months (range 30-143 monthıs), and by the end of December 1992 only three patients had been successfully withdrawn from treatment with corticosteroids after 30,48 , and 128 months, respectively.

\section{Discussion}

A review of more than 1600 chest radiographs of patients with sarcoidosis evaluated at our unit has shown that the presence of a diffuse ground glass pattern on the chest radiograph is an uncommon finding at presentation, but is associated with a distinct clinical profile. These patients were all white and tended to be heavy smokers, they had sarcoidosis of recent onset, and were almost always symptomatic. The disease was responsive to treatment with corticosteroids but frequently relapsed when corticosteroids were tapered or stopped, and several required long term treatment.

Several epidemiological features are noteworthy in this form of sarcoidosis. Firstly, nine of the 10 patients had smoked, and six were current heavy smokers. In two studies from our group the overall prevalence of cigarette smoking among patients with pulmonary sarcoidosis was $31 \%^{12}$ and $39 \%^{13}$ and, among smokers, mean tobacco consumption was 10 cigarettes a day. ${ }^{13}$ In contrast, current smokers in the present study smoked more than 20 cigarettes a day. The high proportion of current and past smokers in this series may explain the observed male predominance.

The origin of ground glass abnormalities in our patients and the reason for the association of these abnormalities with cigarette smoking is unclear. Smoking is known to increase alveolar epithelial permeability which might promote alveolar filling. Because some of our patients were non-smokers and others had stopped smoking alterations in pulmonary epithelial permeability induced by smoking, which are rapidly reversible, ${ }^{15}$ are not the sole factor responsible for the ground glass abnormalities. Smoking is also known to modify the lung immune responses and such changes might predispose to the development of ground glass 
abnormalities. Smoking is not thought to modify the prognosis of sarcoidosis in unselected patients, ${ }^{13}$ however, suggesting that smoking in itself cannot explain the unfavourable outcome of these patients.

It is also noteworthy that all patients, without exception, were white. Sarcoidosis is known to occur more frequently among the black population and, in France, among immigrants from the Caribbean. ${ }^{16}$ In our own series, however, the proportion of white patients with sarcoidosis is approximately $85 \%$. Thus, given the small number of patients identified with ground glass abnormalities, a very large case-control study would be necessary to show that this abnormality is truly more common in the white population.

The presence of hilar or mediastinal adenopathy on the radiograph of all 10 patients, and the observation that chest radiographs taken in the year before diagnosis (when available) were normal, strongly suggest that pulmonary sarcoidosis presenting with a diffuse ground glass radiographic pattern is likely to represent disease of recent onset.

Also striking are the clinical and functional profiles of these patients. Nine presented with severe respiratory symptoms (dyspnoea and cough) and series in which large numbers of unselected patients have been evaluated indicate that respiratory symptoms at presentation are less frequent, particularly in white patients. ${ }^{121617}$ Furthermore, six patients had fine inspiratory crackles mainly in the lower zones. It should be stressed that the presence of inspiratory crackles in our patients was not due to pulmonary fibrosis as they cleared with treatment. In unselected patients crackles are unusual, especially in patients with disease of recent onset who are unlikely to have extensive fibrotic changes. In a study which compares the prevalence of respiratory crackles in various interstitial lung disorders inspiratory crackles were found in only $20 \%$ of patients with sarcoidosis. ${ }^{18}$ In our series the prevalence of crackles in sarcoidosis of recent onset is less than $10 \%$, and is essentially restricted to nonwhite patients in whom sarcoidosis is known to be more severe. ${ }^{19}$ Because crackles themselves suggest the presence of extensive pulmonary disease, it is difficult to determine whether the presence of ground glass abnormalities adds additional prognostic information or merely indicates the presence of "severe" parenchymal involvement.

Although a moderate restrictive pattern associated with an abnormal diffusing capacity is frequently noted in sarcoidosis, ${ }^{2021}$ an important decrease in TLC and TLCO, as observed in our patients, is unusual. ${ }^{223}$ Furthermore, studies on gas exchange have shown that hypoxaemia at rest, which was present in five of our cases, is unusual. ${ }^{21-23}$ Because of these functional abnormalities and the associated clinical symptoms, all patients needed treatment with oral corticosteroids. Although they responded rapidly, long term oral corticosteroid therapy was required to maintain this improvement. This chronic evolution is also uncommon in sarcoidosis of recent onset in white patients. ${ }^{19}$
The activity of the disease at presentation in our patients was supported by the presence of high serum levels of angiotensin converting enzyme in all cases. Although cigarette smoking has been shown to increase serum angiotensin converting enzyme levels in patients with sarcoidosis, ${ }^{13}$ the presence of respiratory symptoms, extrathoracic disease, and hypercalciuria in most of the patients suggests that the elevated levels of serum angiotensin converting enzyme reflect both the clinical activity of their disease and the presence of widespread granulomatous lesions. ${ }^{342425}$ The increased recovery of lymphocytes and mast cells by bronchoalveolar lavage also supports the presence of active disease. ${ }^{14}$ Although the presence of an elevated number of lymphocytes has been reported to be a good prognostic indicator or to be associated with a good response to treatment, or both, ${ }^{2627}$ the presence of mast cells is thought to be associated with a poor prognosis. ${ }^{14}$

Extensive use of thoracic high resolution computed tomographic scanning has led to the more frequent identification of "ground glass" opacities. Focal ground glass abnormalities have been observed in a broad spectrum of lung disorders including sarcoidosis of recent onset. ${ }^{1112829}$ In sarcoidosis these localised abnormalities often occur preferentially around bronchovascular bundles and are associated with other lesions. ${ }^{1028} \mathrm{~A}$ predominant and diffuse ground glass pattern has also been identified on lung high resolution computed tomography in other conditions, ${ }^{2830}$ and disseminated, although not diffuse, ground glass abnormalities have been described in sarcoidosis by this technique. ${ }^{1011} \mathrm{~A}$ ground glass pattern on lung high resolution computed tomography is thought to reflect either minimal thickening of alveolar septa or partial filling of the alveolar air space with fluid or cells." Although the significance of ground glass opacities is incompletely understood, it has been shown to correlate with disease activity in idiopathic pulmonary fibrosis and to be reversible under corticosteroid treatment. ${ }^{31}{ }^{32}$ In a recent study evaluating the correlation between computed tomographic findings and lung histology in bronchiolitis obliterans organising pneumonia biopsy specimens obtained from areas of ground glass opacities contained "alveolar septal inflammation and alveolar desquamation". ${ }^{33}$ Very recently biopsy specimens of localised areas of ground glass pattern have been studied in one patient with sarcoidosis and were found to contain mainly granulomas. ${ }^{34}$

In summary, a diffuse ground glass radiographic pattern at the time of diagnosis of sarcoidosis was observed exclusively in white patients, many of whom were cigarette smokers. The disease proved to be of recent onset and quite active. Although rare, this mode of presentation of the disease is noteworthy because, in our experience, it tends to have a chronic evolution requiring prolonged treatment with oral corticosteroids.

\footnotetext{
1 Scadding JG, Mitchell DN. Prevalence, incidence and modes of presentation. In: Scadding JG, Mitchell DN, eds. Sarcoidosis. 2nd edn. London: Chapman and Hall Medical 1985:43-71.
} 
2 Bascom R, Johns CJ. The natural history and management of sarcoidosis. Adv Intern Med 1986;31:213-42.

3 Thomas PD, Hunninghake GW. Current concepts of the pathogenesis of sarcoidosis. State of the art. Am Rev Respir Dis 1987;135:747-60.

4 Lynch JP, Strieter RM. Sarcoidosis. In: Lynch JP, DeRemee RA, eds. Immunologically mediated pulmonary diseases. Philadelphia: JB Lippincott, 1991:189-216.

5 Rodan BA, Putman CE. Radiological alterations in sarcoidosis. In: Fanburg BL, ed. Sarcoidosis and other granuloma$37-76$.

6 Berkmen YM. Radiologic aspects of intrathoracic sarcoidosis. Semin Roentgenol 1985;20:356-75.

7 Rockoff SD, Rohatgi PK. Unusual manifestations of thoracic sarcoidosis. A₹R 1985;144:513-28.

8 Frazer RG. The radiology of interstitial lung disease. Clin Chest Med 1982;3:475-84.

9 Mönkäre S, Ikonen M, Haahtela T. Radiologic findings in farmer's lung. Prognosis and correlations to lung function. Chest 1985;87:460-6.

10 Brauner MW, Grenier P, Mompoint D, Lenoir S, de Cremoux H. Pulmonary sarcoidosis: evaluation with highresolution CT. Radiology 1989;172:467-71.

11 Engeler CE, Tashiian JH, Trenker SW, Walsh JM. Groundglass opacity of the lung parenchyma: a guide to analysis glass opacity of the lung parenchyma: a guide to
with high-resolution CT. $A \nVdash R$ 1993;160:249-51.

12 Hance AJ, Basset F, Saumon G, Danel C, Valeyre D, Battesti $\mathrm{JP}$, et al. Smoking and interstitial lung disease. Ann NY Acad Sci 1986;465:643-56.

13 Valeyre D, Soler P, Clerici C, Pre J, Battesti JP, Georges R, et al. Smoking and pulmonary sarcoidosis: effect of cigarette smoking on prevalence, clinical manifestations, alveolitis, and evolutior

14 Bjermer L, Rosenhall L, Angström T, Hällgren R. Predictive value of bronchoalveolar lavage cell analysis in sarcoidosis. Thorax 1988;43:284-8.

15 Mason GR, Uszler JM, Effros RM, Reid E. Rapidly reversible alterations of pulmonary epithelial permeability induced by smoking. Chest 1983;83:6-11.

16 Siltzbach LE, James DG, Neville E, Turiaf J, Battesti JP, Sharma OP, et al. Course and proonosis of sarcoidosis around the world. $A m \mathcal{F}$ Med 1974;57:847-52.

17 Hillerdal G, Nöu E, Osterman K, Schmekel B. Sarcoidosis: epidemiology and prognosis. Am Rev Respir Dis 1984; 130:29-32.

18 Epler GR, Carrington CB, Gaensler EA. Crackles (rales) in the interstitial pulmonary diseases. Chest 1978;73:333-9.

19 Israel HL, Karlin P, Menduke H, Delisser OG. Factors affecting outcome of sarcoidosis. Ann NY Acad Sci 1986; 465:609-18.

20 Winterbauer RH, Hutchinson JF. Clinical significance of pulmonary function tests. Use of pulmonary tests in the management of sarcoidosis. Chest 1980;78:640-7.
21 Williams MH. Pulmonary function in sarcoidosis. In: Fanburg, BL, ed. Sarcoidosis and other granulomatous diseases of the lung. New York: Marcel Dekker, 1983:77-98.

22 Lamberto C, Saumon G, Loiseau P, Battesti JP, Georges R. Respiratory function tests in recent pulmonary sarcoidosis in special reference to small airways. In: Chrétien J, Marsac J, Saltiel JC, eds. Proceedings of the 9th international conference on sarcoidosis and other granulomatous disorders. Paris: Pergamon Press, 1981:280-3.

23 Dunn TL, Watters LC, Hendrix C, Cherniack RM, Schwarz MI, King TE. Gas exchange at a given degree of volume restriction is different in sarcoidosis and idiopathic pulmonary fibrosis. Am $f$ Med 1988;85:221-4.

24 Ainslie GM, Benatar SR. Serum angiotensin converting enzyme in sarcoidosis: sensitivity and specificity in diagnosis: correlations with disease activity, duration, extrathoracic involvement, radiographic type and therapy. $Q \mathcal{F}$ Med 1985;218:253-70.

25 Meyrier A, Valeyre D, Bouillon R, Paillard F, Battesti JP, Georges $\mathbf{R}$. Different mechanisms of hypercalciuria in sarcoidosis: correlations with disease extension and activity. Ann NY Acad Sci 1986;465:575-86.

26 Ward K, O'Connor C, Odlum C, Fitzgerald MX. Prognostic value of bronchoalveolar lavage in sarcoidosis: the critical influence of disease presentation. Thorax 1989;44: influence.

27 Foley NM, Coral AP, Tung K, Hudspith BN, James DG, Johnson NMc. Bronchoalveolar lavage cell counts as a predictor of short term outcome in pulmonary sarcoidosis. Thorax 1989;44:732-8.

28 Müller NL, Miller RR. Computed tomography of chronic diffuse infiltrative lung disease. State of the art. Am Rev Respir Dis 1990;142:1206-15, 1440-8.

29 Grenier $P$, Valeyre D, Cluzel $P$, Brauner MW, Lenoir $S$, Chastang C. Chronic diffuse interstitial lung disease: diagnostic value of chest radiography and high-resolution $\mathrm{CT}$. Radiology 1991;179:123-32.

30 Bergin CJ, Wirth RL, Berry GJ, Castellino RA. Pneumocystic carinii pneumonia: CT and HRCT observations. $\mathcal{f}$ Comput Assist Tomogr 1990;14:756-9.

31 Müller NL, Staples CA, Miller RA, Vedal S, Thurlbeck WM, Ostrow DN. Disease activity in idiopathic pulmonary fibrosis: CT and pathologic correlation. Radiology 1987:165:731-4.

32 Lee JS, Im J-G, Ahn JM, Kim YM, Han MC. Fibrosing alveolitis: prognostic implication of ground-glass attenuation at high-resolution CT. Radiology 1992;184: $451-4$

33 Nishimura K, Itoh H. High-resolution computed tomographic features of bronchiolitis obliterans organizing pneumonia. Chest 1992;102:26S-31S.

34 Nishimura $K$, Itoh $H$, Kitaichi $M$, Nagai $S$, Izumi $T$. Pulmonary sarcoidosis: correlation of CT and histopathologic findings. Radiology 1993;189:105-9. 